\title{
Glass containers under filling: a possible risk enhancement for delamination
}

\begin{abstract}
Among the factors that can affect the glass surface chemical durability, $\mathrm{pH}$, salts concentration, complexion agents presence, etc., the vial under filling is rarely considered. United States Pharmacopeia (USP) $<660\rangle$ test for glass surface chemical durability, prescribes a filling volume of $90 \%$ of glass containers brimful capacity but most of glass containers for inject able solutions are filled less than or by far less than $90 \%$. Any time the filling volume is lower than the container nominal one, glass surface attack can be enhanced due to the increasing unfavourable surface/volume ratio. No regulation there is on this topic neither in the European Pharmacopeia nor in the United States Pharmacopeia.

The present study shows the trend of the glass surface hydrolytic attack in molded small-volume $23 \mathrm{~mL}$ type I glass containers with decreasing filling volumes from $90 \%$ to $30 \%$ of the brimful capacity. Hydrolytic attack was performed by autoclaving according to the European Pharmacopeia or United States Pharmacopeia for $1 \mathrm{~h}$ at $121^{\circ} \mathrm{C}$ with water and with a citric acid solution $0,024 \mathrm{M}(0.5 \% \mathrm{w} / \mathrm{v})$ at $\mathrm{pH} 7.4$. Silicon release into the attack solutions was analysed by Inductively Coupled Plasmna Atomic Emission Spectrophotometry.

In case of filling with water, silicon release and titration by $\mathrm{HCl} 0,01 \mathrm{M}$ are in good agreement. More than three times of the release increment was experienced by decreasing the filling volume till $1 / 3$. Glass surface wetted by the solution, headspace surface and the unfavourable ratio surface/volume are all responsible for the global glass release. Completely different is the behaviour of the silicon release in presence of the citric acid solution for which an explication is assessed. Correlations between silicon release from the glass surface, $\mathrm{HCl}$ titration, surface/volume ratio, extraction power of the citric acid solution and the role of $\mathrm{pH}$, are shown giving also a practical advice for the packaging of small volume solutions, considering that it is better to fill up to $90 \%$ a small container instead of under fill a bigger one. The choice can be addressed by calculating the lowest inner surface/volume ratio.
\end{abstract}

Keywords: glass chemical durability, hydrolytic resistance, borosilicate type 1 glass, silicon release, $\mathrm{pH}$
Volume 5 Issue 6 - 2018

\author{
Biavati A,' Ferrarini A, ${ }^{2}$ Marchegiani $M,{ }^{2}$ \\ Poncini $M,{ }^{2}$ Severi $G^{2}$ \\ 'Glass Technology Consultant, USP Glass Expert Panel Member \\ ${ }^{2}$ Bormioli Rocco SpA, Viale Martiri della Libertà, Italy
}

\section{Correspondence: Biavati A, Glass Technology Consultant, USP Glass Expert Panel Member,Via Gramsci 25, 43022} Montechiarugolo, Italy, Email alberto.biaveti@virgilio.it Received: September 25, 2018 | Published: December 03,
2018

\section{Introduction}

Many glass containers for inject able solutions are filled less or by far less than $90 \%$ of glass containers brimful capacity, that is the filling volume prescribed by United States Pharmacopeia (USP) $<660>$ test for glass surface chemical durability. To a lower filling volume corresponds a potentially increased glass surface attack, but how much can increase the attack on the glass surface? Like all the packaging materials, glass can show limits under some harsh usage conditions so it is of extreme importance to have a knowledge of the factors that can affect the glass surface chemical durability ${ }^{1}$ in order to better address the stability trials of a pharmaceutical preparation, as suggested by United States Pharmacopeia (USP) $<1660>.{ }^{2}$ The appearance in solution of visible shiny needle shaped particles (named lamellae or better flakes) after some conditioning time, is a typical macroscopic phenomenon of a strong chemical attack on the glass surface, triggered by time and temperature. ${ }^{3}$ Before being face with a visible or sub visible delaminating phenomenon it is possible to foresee negative results by a periodic check of silicon release trend from the glass. In any case, lamellae formation could not be related to a high silicon release, because it could be an independent phenomenon. ${ }^{4}$ In a borosilicate glass also boron could be considered as a glass chemical durability index but it is less favourable because of its lower concentration about 1/6-1/7 of silicon.

The other oxides present in the glass composition are approximately released in amounts similar to their ratio with silica. Only the silica/ $\mathrm{Na}_{2} \mathrm{O}$ ratio is lower due to the higher sodium concentration in the glass surface layer ${ }^{5}$ and its propensity to be released more easily from the glass network.

Flakes are not the simple result of a strong chemical attack on the glass surface, but usually depend on the surface glass composition that could have been locally enriched in silica after the evaporation of borates following a forming-melting process of the container or after a surface silica treatment. In the lamellae forming process both mechanisms of chemical hydration of the silica layer and its physical detachment by mechanical stress due to the different composition of the underneath glass, are involved. ${ }^{6}$ The physical relationship to flakes removal can be ascribed to the different expansion coefficients of the silica-rich hydrated layer in comparison with the glass bulk underneath.

In addition to or alternatively to the mentioned mechanism of lamellae (flakes) forming it is also quite probable that harsh attack 
conditions can promote an important silicon release without any delaminating, that is a considerable glass surface corrosion can happen without flakes development.

USP $<1660>^{2}$ although provides both information about factors that affect the glass surface durability and recommends approaches to evaluate the potential propensity for glass flakes production, does not take into consideration the possible influence of vials under filling. Literature gives scanty information on this topic. An interesting theoretical approach to vial geometrical shape and under filling consequences was done by Gualandi. ${ }^{7}$ When the whole inner surface of a vial is wetted by a pharmaceutical aqueous solution, all the glass components released by the glass surface as a consequence of the chemical interactions, are subjected to concentrate the more the less the water volume, so $\mathrm{pH}$ can increase more quickly in small volumes accelerating the surface chemical attack.

With the purpose to experience the under filling influence, the present study shows the trend of the glass surface hydrolytic attack by decreasing filling volumes from $90 \%$ to $30 \%$ of the brimful capacity. Trials were performed on $23 \mathrm{~mL}$ type I vials of molded borosilicate glass by autoclaving according to EP or USP for $1 \mathrm{~h}$ at $121^{\circ} \mathrm{C}$ with water and with a citric acid solution $0,024 \mathrm{M}(0.5 \% \mathrm{w} / \mathrm{v})$ at $\mathrm{pH} 7.4$. Autoclaving at $121^{\circ} \mathrm{C}$ for $1 \mathrm{~h}$ corresponds approximately to five years of contact glass-aqueous solution at room temperature ${ }^{8,9}$ so, where applicable, it is a fast method of ageing simulation. Silicon release into the attack solutions was analysed by ICPAES and water titrated by $\mathrm{HCl} 0.01 \mathrm{M}$.

Further aim of the present work was to evaluate the contribute of the head space to the whole inner surface release and to point out the importance of the $\mathrm{S} / \mathrm{V}$ ratio (Surface/Volume) to minimize the chemical attack and consequently the delamination risk for very small capacity vials. The last was experienced by comparing the surface chemical attack by the same water volume of $7 \mathrm{ml}$ in two vials of $23 \mathrm{~mL}$ and $8 \mathrm{~mL}$ that means respectively a filling volume of $30 \%$ and $90 \%$ of their brimful capacity.

\section{Materials and methods}

An autoclave Asal Vapormatic 770, controlled by a Programmable Logic Controller (PLC) was used for the autoclaving trials, according to the procedure described in the United States Pharmacopeia $<660>$ and European Pharmacopeia 3.2.1 ( $1 \mathrm{~h}$ at $121^{\circ} \mathrm{C}$ ). Trials were performed with deionized water of conductivity lower than $0.2 \mu \mathrm{S}$ from a RD 60 Elettracqua deionizer and with $0.024 \mathrm{M}(\mathrm{M} / \mathrm{L}, 0.5 \%$ $\mathrm{w} / \mathrm{v}$ ) citric acid at $\mathrm{pH} 7.4, \mathrm{pH}$ adjusted by diluted $\mathrm{LiOH}$ solution. $\mathrm{pH}$ determination by a pHmeter WTW L2 with Hamilton electrodes. All reagents from Carlo Erba RPE Reagents. Small capacity 23 and $8 \mathrm{ml}$ molded type I borosilicate glass containers were chosen to enhance the glass surface attack due to their high surface/volume ratio. Glass composition of the tested vials is shown in Table 1 .

Table I Borosilicate flint glass composition

\begin{tabular}{ll}
\hline $\mathrm{SiO}_{2} \%$ & 70 \\
$\mathrm{Al}_{2} \mathrm{O}_{3}$ & 5.5 \\
$\mathrm{CaO}$ & 1.1 \\
$\mathrm{BaO}$ & 2.5 \\
$\mathrm{~B}_{2} \mathrm{O}_{3}$ & 11.5 \\
$\mathrm{Na}_{2} \mathrm{O}$ & 7.6 \\
$\mathrm{~K}_{2} \mathrm{O}$ & 1.8 \\
\hline
\end{tabular}

Autoclaving trials were performed with $23 \mathrm{~mL}$ glass vials filled with water or citric acid $0.024 \mathrm{M}$, up to $90,70,50$ and $30 \%$ of the brimful capacity as shown in Figure 1. Silicon analysis was performed in the attack solutions by ICP Thermo Fisher Dual 6300 just after the autoclaving. Each trial was performed with about 20 vials and replicated at least four times to increase accuracy.

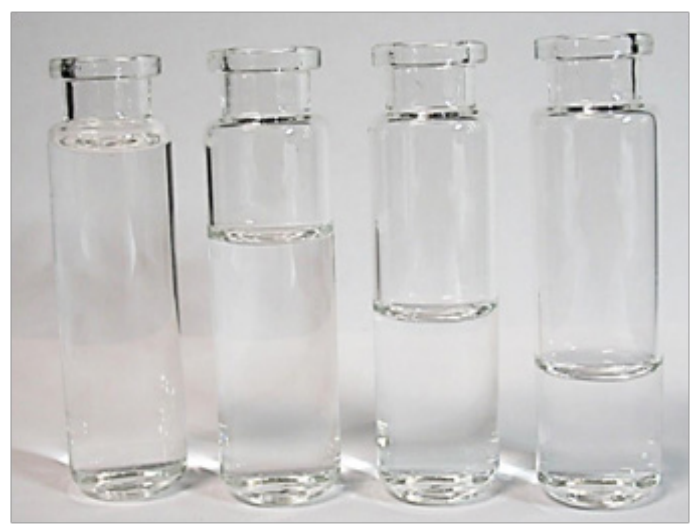

Figure I Examples of filling and under filling, from left to right: $90,70,50,30 \%$.

\section{Results and discussion}

Figure 2-4 show the results of autoclaving trials with $\mathrm{HCl}$ titration and silicon release plotted in function of the percentage of filling. In correspondence of each plotted point the range of measure variation is also indicated. Figure 2 shows that the titration value with the lowest filling volume exceeds the USP $<660>$ titration limit. The final $\mathrm{pH}$ values were $7.0 \pm 0.1$ with $90 \%$ of filling and $7.4 \pm 0.2$ with $30 \%$ of filling.

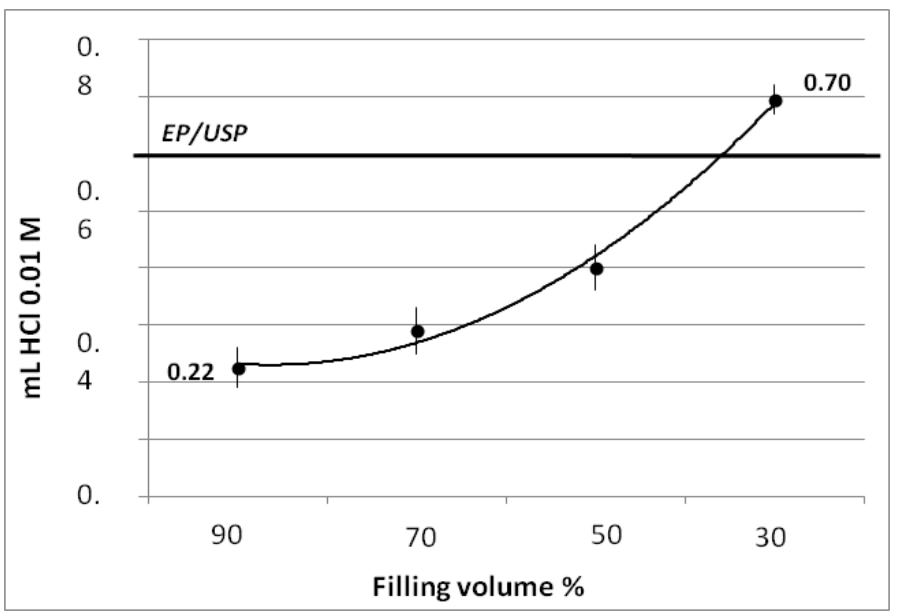

Figure $2 \mathrm{Ih}$ at $121^{\circ} \mathrm{C}$ with water, $\mathrm{HCl} 0.01 \mathrm{M}$ titration of $23 \mathrm{~mL}$ type I molded vials.

As expected the increasing values of both titration and silicon release according to a second degree function, are in agreement with the increasing attack rate by a more and more aggressive solution due to both $\mathrm{pH}$ increasing and glass surface release that concentrates the more the lower the volume. By dividing the highest value of $\mathrm{HCl}$ titration and of Si release at the filling volume of $30 \%$ by the lowest ones at $90 \%$ of filling volume, an increase factor (IF) is obtained as follows:

$$
\begin{aligned}
& \text { Titration - water, } \mathrm{IF}_{\mathrm{WT}}: \mathbf{0 . 7 0 / 0 . 2 2} \mathbf{3 . 2} \\
& \text { Si release - water, } \mathrm{IF}_{\mathrm{WSi}}: \mathbf{3 . 8} / \mathbf{1 . 1 5} \mathbf{3 . 3}
\end{aligned}
$$




\section{Si release - citric acid, $\mathrm{IF}_{\mathrm{CA}}: \mathbf{1 1 . 6 / 7 . 5 5} 1.5$}

$\mathrm{IF}_{\mathrm{WT}}$ and $\mathrm{IF}_{\mathrm{WSi}}$ factors are similar, while the $\mathrm{IF}_{\mathrm{CA}}$ factor of citric acid solution is quite different. This difference is better shown by a mathematical conversion of the plotted second degree functions (Figure 2-4) into linear first degree functions as shown in Figure 5.

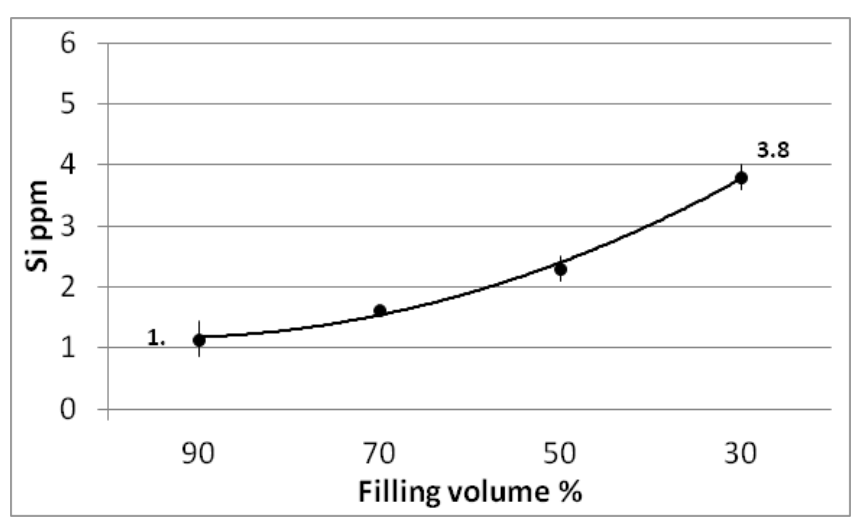

Figure $3 \mathrm{Si}$ release of $23 \mathrm{~mL}$ type I molded vials, Ih at $121^{\circ} \mathrm{C}$ with water.

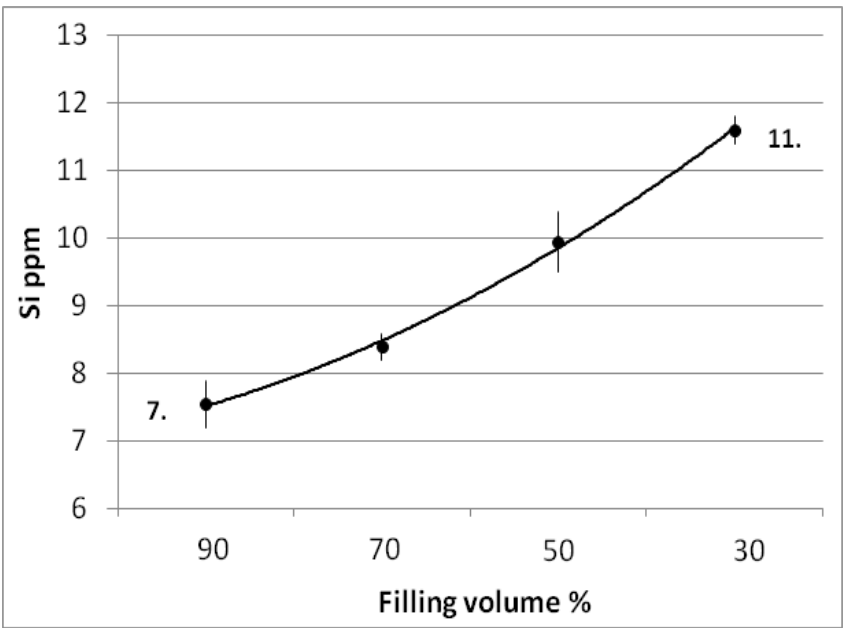

Figure $4 \mathrm{Si}$ release of $23 \mathrm{~mL}$ type I molded vials, $\mathrm{Ih}$ at $121^{\circ} \mathrm{C}$ with citric acid 0.024M, $\mathrm{pH} 7.4$.

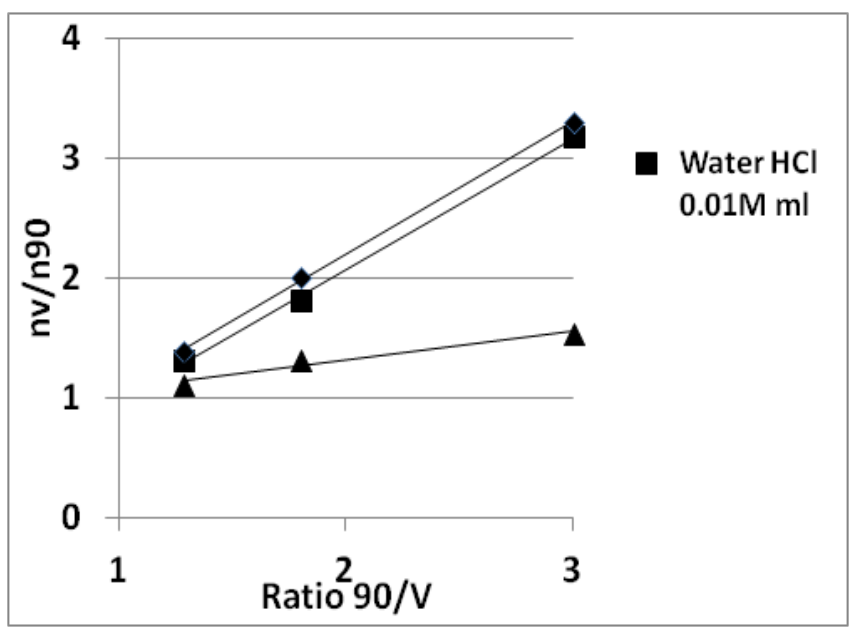

Figure $\mathbf{5}$ Linear correlations between titration and Si release.

The conversion is obtained by plotting in ordinate axis the ratio:

$\mathrm{n}_{\mathrm{v}}$ (value $\mathrm{n}$ at filling volume $\mathrm{V} \%$ ) $/ \mathrm{n}_{90}$ (value $\mathrm{n}$ at filling volume $90 \%)$

and in abscissa axis the ratio:

90/V (with $\mathrm{V}=70,50,30 \%$ ).

Figure 5 shows a good linear correlation between the glass release (Si and $\mathrm{HCl}$ titration) ratio $\mathrm{n}_{\mathrm{v}} / \mathrm{n}_{90}$ and the filling ratio $90 / \mathrm{V}$. The straight line equations for water $\mathrm{Si}$ release $\left(\mathrm{y}=1.0974 \mathrm{x}-0.124, \mathrm{R}^{2}=0.99\right)$ and the one for $\mathrm{HCl}$ titration $\left(\mathrm{y}=1.108 \mathrm{x}-0.0174, \mathrm{R}^{2}=0.99\right)$ are each other linearly correlated with quite similar angular coefficients, so substantially parallel straight lines were obtained. The correlation found between titration and Si release seem to be good unlike titration and alkali release, that are considered not equivalent. ${ }^{10}$

The behaviour of the citric acid solution is quite different as shown by the lower slope of the straight line of Figure $5(\mathrm{y} 0.239 \mathrm{x}+0.838$, $\mathrm{R}^{2}=0.95$ ). If there should be only a chemical attack on the $30 \%$ of inner surface in contact with the citric acid solution, the silicon release should be $1 / 3$ of the one experienced at $90 \%$ of filling, plus the contribute of steam extraction from the head space, since citric acid does not evaporate. In this case the silicon release should be $\sim 5 \mathrm{ppm}$, less than one half of the experienced $11.6 \mathrm{ppm}$. As a matter of fact citric acid solution wetted at least part of the head space during the vial filling and probably it can someway diffuse by surface tension during autoclaving. Besides the following should be considered:

Solution buffering, the $\mathrm{pH}$ remains almost constant by increasing only of 0.1-0.2 units after autoclaving; silicon release extent already high at $90 \%$ of filling that reasonably cannot increase so much even decreasing the volume down to $30 \%$, considering also a possible extraction limit of reaction. ${ }^{11}$ As a matter of fact, by decreasing the filling volume from $90 \%$ to $30 \%$ it is foreseeable to find at least an increase of 3times of both titration and $\mathrm{Si}$ release in not buffered solutions, according to the following ratio change Figure 6.

$\mathrm{S} / \mathrm{V}_{30} / \mathrm{S} / \mathrm{V}_{90} ; 5.5 / 1.8 \sim 3.1$

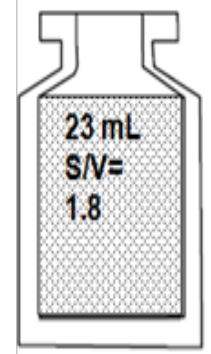

Titration limit $0.60 \mathrm{~mL}$ Filling vol. $90 \%=21 \mathrm{~mL}$ Titration value $0.22 \mathrm{~mL}$

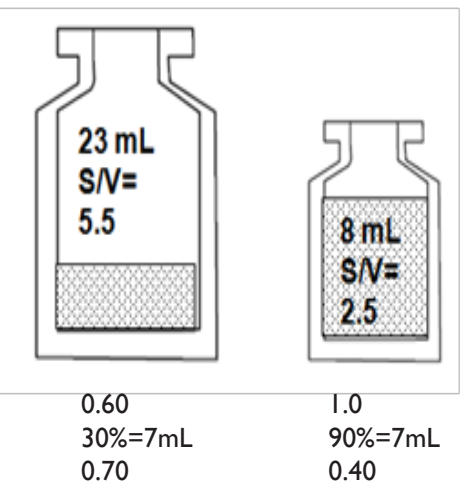

Figure 6 Comparison of surface to volume ratios for 23 and $8 \mathrm{~mL}$ vials.

The approximate $5 \%$ of further average increase of both $\mathrm{IF}_{\mathrm{WT}}$ factor 3.2 and $\mathrm{IF}_{\mathrm{wSi}}$ factor 3.3, are consistent with the higher concentration of the glass release in the lowest volume with a consequent further chemical attack. This moderate increase of only $5 \%$ should indicate a moderate glass surface attack at the worse $\mathrm{pH}$ experienced of 7.4. It is foreseeable that worse release consequences will develop in lower chemical durable glasses. Both $\mathrm{IF}_{\mathrm{wT}}$ and $\mathrm{IF}_{\mathrm{wSi}}$ factors should also 
confirm that the chemical attack by the steam in the head space is similar to that of the water contacting the glass surface.

Considering that the higher the $\mathrm{S} / \mathrm{V}$ ratio the higher will be the glass hydrolytic attack, the comparison between filling volumes and titration values of Figure 6 point out that a smaller capacity vial with a more favorable $\mathrm{S} / \mathrm{V}$ ratio, should be the advisable choice to avoid the consequences of under filling with a bigger capacity vial.

In fact Figure 6 shows that the same volume of $7 \mathrm{~mL}$ is only the $30 \%$ of filling volume for the $23 \mathrm{~mL}$ vial but the $90 \%$ of the $8 \mathrm{ml}$ vial with a considerable advantage to decrease the $\mathrm{HCl} 0.01 \mathrm{M}$ titration value from 0.70 to $0.40 \mathrm{~mL}$. The last complies with the titration limit of USP. For the same reason the choice of the most favorable capacity vial can be better addressed in case of filling with an aggressive solution.

\section{Conclusion}

Autoclavings of $1 \mathrm{~h}$ at $121^{\circ} \mathrm{C}$ were performed on $23 \mathrm{~mL}$ borosilicate type I molded glass containers, with water and citric acid $0,024 \mathrm{M}$, by decreasing the filling volume from $90 \%$ down to $30 \%$ of the brimful capacity. A significative increase of the glass surface attack was experienced by the $\mathrm{HCl} 0.01 \mathrm{M}$ titration values even to exceed the USP limit in case of $30 \%$ filling volume.

Good linear correlations were obtained between Si release and $\mathrm{HCl}$ titration with water, by plotting the ratio $\mathrm{n}_{\mathrm{v}} / \mathrm{n}_{90}$ (value at filling volume $\mathrm{V}$ and value at filling volume $90 \%$ ) in function of the filling ratio 90/V. Two almost parallel straight lines were obtained.

The attack by steam on the head space was experienced to be similar to water in direct contact with the glass surface. The increase of more than 3times of the glass release with water by decreasing the filling volume to $30 \%$, is to be ascribed to both the glass release concentration in a lower and lower volume and the consequent $\mathrm{pH}$ increase that enhances the surface chemical attack. In case of an aggressive buffered solution like citric acid $0.024 \mathrm{M}$, even considering that the silicon extraction was 3 times the one obtained by water with $30 \%$ of filling volume, an enhancement of only 1.5 times of the surface chemical attack was experienced.

The reason of the lower enhancement of 1.5 times in comparison with 3 times that of water, should be ascribed to the following reasons:

a. Only a little citric acid could spread on the head space surface.

b. Possible "dilution" effect by the steam presence on the head space surface. c. Silicon release trend towards a limiting extraction rate.

Glass vials filling with pharmaceutical preparations mainly in case of known aggressive solutions, should be also evaluated considering the surface attack enhancement in case of under filling as further delamination promoting factor.

\section{Acknowledgments}

None

\section{Conflicts of interest}

The Authors declare that they do not have any financial or nonfinancial competing interests related to the content of the manuscript.

\section{References}

1. Clark DE, Pantano CG, Hench LL. Corrosion of Glass. New York; 1979.

2. $<1660>$ Evaluation of the Inner Surface Durability of Glass Containers

3. Guadagnino E, Zuccato D. Delamination Propensity of Pharmaceutical Glass Containers by Accelerated Testing with Different Extraction Media. PDA J Pharm Sci Technol. 2012;66(2):116-125.

4. Fouhert M, Iacocca R, Shi A. New Findings into Glass Delamination Phenomenon in Parenteral Packaging, a Materials Science Perspective. PDA Annual Meeting Las Vegas. 2007.

5. Guadagnino E, Verità M, Furlani C. Aluminium Release of Pharmaceutical Glass Containers: Determination by GFAAS in the Extract Solutions and Study of the Inner Surfaces by XPS and SIMS. Glastechnische Berichte. 1991;64(7).

6. Weisser M, Bange K. Sophisticated Methods Available to Analyze Glass Corrosion. The Glass Researcer. 2000;9(2):16-21.

7. Gualandi G. Surface Hydrolytic Resistance of Glass Containers for Pharmaceutical Use. Pharmeuropa. 2000;12(3):396-400.

8. Bacon FR. The Chemical Durability of Silicate Glass. Glass Ind. 1968;49

9. Biavati A. Correlation between Hydrolytic Ion Release and $\mathrm{pH}$ Changes in Type II Glass Containers. Pharm.Ind. 1997;59(2):175-178.

10. European Pharmacopoeia 9.0, 3.2.1 Glass Containers for Pharmaceutical Use, Annex-Test for Surface Hydrolytic Resistance-Determination by Flame Spectrometry. 2017.

11. Biavati A, Poncini M, Ferrarini A, et al. Complexing Agents and $\mathrm{pH}$ Influence on Chemical Durability of Type I Molded Glass Containers. PDA J Pharm Sci Technol. 2017;71(4):306-316. 